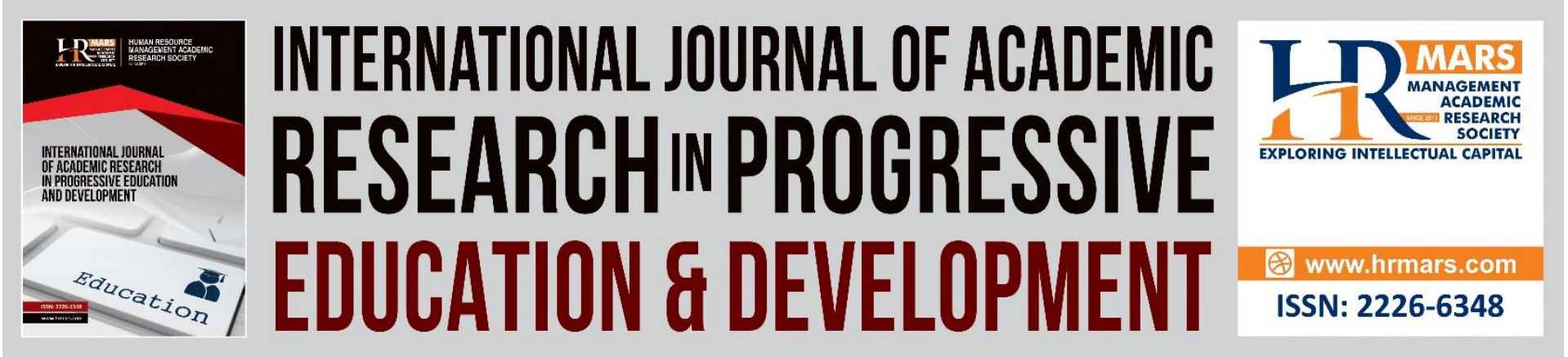

\title{
Interactive Multimedia Website Assisted in Learning Basic Japanese Language
}

\section{Muhammad Alif Redzuan Abdullah, Sanimah Hussin}

To Link this Article: http://dx.doi.org/10.6007/IJARPED/v10-i3/10561

DOI:10.6007/IJARPED/v10-i3/10561

Received: 01 June 2021, Revised: 23 July 2021, Accepted: 17 July 2021

Published Online: 20 August 2021

In-Text Citation: (Abdullah \& Hussin, 2021)

To Cite this Article: Abdullah, M. A. R., \& Hussin, S. (2021). Interactive Multimedia Website Assisted in Learning Basic Japanese Language. International Journal of Academic Research in Progressive Education and Development, 10(3), 710-724.

Copyright: (C) 2021 The Author(s)

Published by Human Resource Management Academic Research Society (www.hrmars.com)

This article is published under the Creative Commons Attribution (CC BY 4.0) license. Anyone may reproduce, distribute, translate and create derivative works of this article (for both commercial and non-commercial purposes), subject to full attribution to the original publication and authors. The full terms of this license may be seen

at: http://creativecommons.org/licences/by/4.0/legalcode

\section{Vol. 10(3) 2021, Pg. 710 - 724}

\section{http://hrmars.com/index.php/pages/detail/IJARPED}

JOURNAL HOMEPAGE

Full Terms \& Conditions of access and use can be found at http://hrmars.com/index.php/pages/detail/publication-ethics 


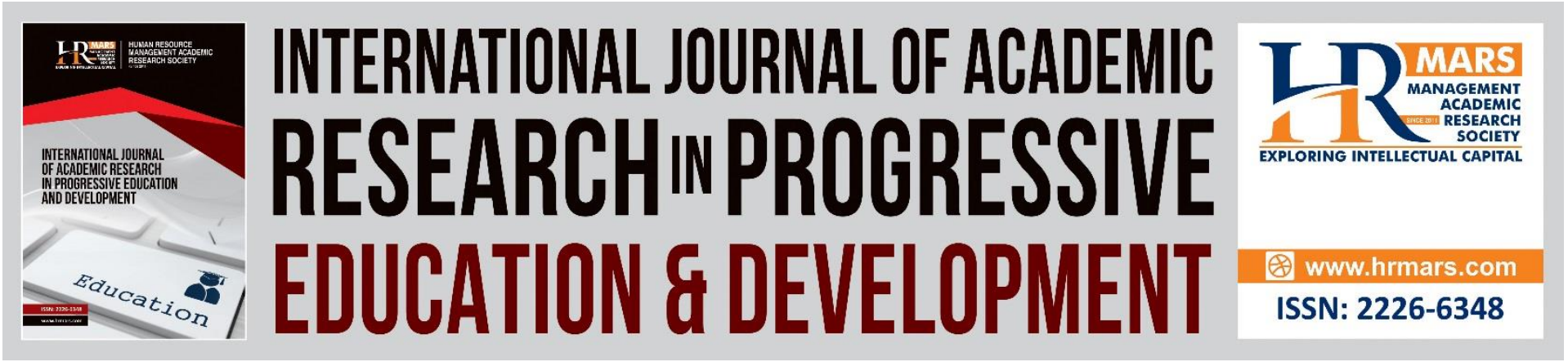

\title{
Interactive Multimedia Website Assisted in Learning Basic Japanese Language
}

\author{
Muhammad Alif Redzuan Abdullah, Sanimah Hussin \\ Faculty of Modern Languages and Communication, Universiti Putra Malaysia, Selangor, \\ Malaysia \\ Email:muhammadalif@upm.edu.my,sanimah@upm.edu.my
}

\begin{abstract}
The mastery of all four language skills that include listening, speaking, reading, and writing skills can determine the level of the students in learning the Japanese language. Therefore, the students should have understood the meaning and usage of vocabulary and grammar to achieve a certain level of proficiency in learning the Japanese language. Learners must acquire a sufficient amount of Japanese vocabulary items to achieve competency in these four language skills. This research aims to identify the students' perceptions of using the interactive multimedia website in acquiring vocabulary and grammar among Japanese language learners in UPM. This research also analyses the participants' behavior while learning the Japanese language using the interactive multimedia website. This research has applied a qualitative data collection method that focused on interviews and observation. The researcher has developed an interactive multimedia website to enable users to learn Japanese words and grammar using an e-learning platform application that incorporates various multimedia tools such as animation, songs, graphics, and movies. Moreover, the Internet might prove to be successful in turning traditional classrooms into communicative and student-centered classrooms. The result indicates the need for an interactive multimedia website in learning vocabulary and grammar in the Japanese language more engaging, apart from facilitating independent learning among Japanese language learners in UPM.
\end{abstract}

Keywords: Interactive, Multimedia, Website, Japanese Language, E-learning

\section{Introduction}

The total number of Japanese language learners in Malaysia in 2018 was 39,247 which marked an increase of about 18.1\% from 2021 (Survey Report on Japanese-Language Education Abroad, 2021). The statistics clearly shows that among Malaysians, Japanese is one of the most popular foreign languages after Chinese and Arabic. In today's borderless job market era, the ability to communicate in a third language especially a foreign language is an added value for university graduates (Abdullah, \& Hussin, 2020; Abdullah \& Hussin, 2019). One of the aspirations outlined in the Malaysia Education Blueprint 2015-2025 (Higher Education) is the emphasis on acquiring at least one additional foreign language among students in higher education institutions. 
The "Look East Policy" introduced by Tun Dr Mahathir Mohamed in 1982 has given fresh impetus to the exposure of Japanese language and culture. Many Malaysians were sent to study in Japanese universities; some of whom have become experts in facilitating technology transfer from Japan to Malaysia. According to Abdullah \& Hussin (2020) Japanese language is popular among students of higher education institutions in Malaysia especially in the $21^{\text {st }}$ century. In fact, it is learned even before students decide to explore into the Japanese popular cultures due to the easy access to multiple Internet websites connected to popular Japanese culture or travel to Japan through mobility programs since travelling to Japan has become cheaper because of the Memorandum of Understanding between UPM and Japanese universities. Besides that, many Japanese companies have recruited some local talents with Japanese language background to work with them in Malaysia through job recruiting companies such as JAC Recruitment Company, Sakura Recruitment Company, JapaneseJobs.com, and Jobstreet.com. All these opportunities have increased the popularity of the Japanese language among UPM students, and it is seen as a milestone among UPM Japanese language students to explore the Japanese language and culture further.

Language learning generally focuses on four skills: listening, speaking, reading, and writing. In Japanese language particularly, competency in these four skills cannot be achieved without a good mastery of the Japanese vocabulary (Abdullah, 2005). According to the Department of State's Foreign Service Institute, comprehending the Japanese language requires three to four times more vocabulary than comprehending the European languages. This shows that learning the Japanese language is three to six times more difficult than learning other common European languages. The basic Japanese textbook that is currently being used to teach UPM students in learning the Japanese language for a total of 142 hours throughout the three semesters consists of 1,000 words. Though it involves a large corpus of vocabulary items and may seem like a heavy load to students, there is no guarantee that these students will be able to use the language competently at the end of the three semesters.

The main problem faced by students is memorizing new vocabulary items and recalling them when necessary, during a conversation or other language activities (Abdullah, 2014). Memorizing many vocabulary items through dictionary search or a course textbook is not an easy task for first time learners. However, advancement in the technology developed for educational purposes has created a new paradigm shift in the delivering of the Japanese language lessons to students in UPM. According to Kahoot-Edtrends (2018), 68\% of generation $\mathrm{Z}$ and digital natives prefer mobile application, $48 \%$ prefer online learning tools, $39 \%$ prefer watching video, 34\% prefer using social media, $16 \%$ prefer video conferencing, $10 \%$ prefer listening to lectures, and only $1 \%$ prefer using books for their training programs in the workplace. The reasons behind these choices are that the activities involve more handson training that encourage engagement in the activities apart from being interactive, flexible, and allow for longer training time. Therefore, developing an interactive multimedia website which incorporates multimedia tools such as audio assisted vocabulary learning, animated dialogues, digital flash cards, and online quizzes would enable users to learn basic Japanese language vocabulary and grammar using the e-learning platform. Thus, the usage of an interactive multimedia website might prove to be successful in turning traditional classrooms into communicative and student-centred learning classrooms. 
In the case of learning Japanese language as an elective foreign language subject in UPM, the practical use of an interactive multimedia website in an e-learning platform application has not been studied. Thus, the present study aimed to explore the relationship between the use of an interactive multimedia website and acquisition of vocabulary and grammar among Japanese language learners in UPM.

\section{Research Questions}

This study is carried out to answer the following research questions:

i) What is the respondents' perception on the use of interactive multimedia website in acquiring vocabulary and grammar among Japanese language learners.

ii) What is the feedback of respondents on the overall usage of the use of interactive multimedia website in acquiring vocabulary and grammar among Japanese language learners.

\section{Literature Review}

E-learning or web-based learning is defined as applying innovative technologies and approaches in the field of teaching and learning that can be used beyond time and space. Moreover, e-learning not only allows knowledge to be accessed anywhere, any time, and by anyone, but it also guides learners in attaining the exact skills and knowledge at the exact time to function as active, self-reflected, and collaborative participants in the informationbased society (Harasim, 2000). Nevertheless, most E-learning applications are developed with little consideration on issues that affect E-learning because marketing advertising and technologies are still the main forces that drive the construction process (Buendia \& DiazPerez, 2003). Thus, it is important that developers of web-based learning or E-learning understand that web-based learning is a product of a creative act of development and not a repetitive act of manufacturing. This is to avoid faulty definition of requirements, design solutions, quality, and maintainability.

Web-based learning courseware with unattractive design, scattered content, and low-quality animation will kill the interest and motivation of students learning basic Japanese. Kamaruddin (2010) stated that to save time and develop a web-based learning that is easy, developers tend to create a web page with simple designs, unattractive animations, and contain pure graphics without realising that the application would bore the students and thus, refrain them from using the applications in their learning. Moreover, developers rely more on their personal experience and knowledge and not on the scientific pedagogical knowledge when designing a web-based learning courseware. Developers should work hand in hand with other stakeholders in developing an effective, accurate, and robust web-based learning courseware.

According to Sabri et al (2010), web-based learning can be an interesting tool that inspires and motivates students during the learning process. In fact, multimedia web-based learning offers a lot of advantages compared to the traditional teaching style. Using books that are not accompanied by audio files can bore the students since they are not able to learn how to pronounce the words. Besides, this makes it difficult for them to memorize the words learnt from the textbook easily. With the website on e-learning platform, students can access, use, and learn Japanese language continuously throughout a week. Hence, there is no limitation to their learning if they have an Internet or Wi-Fi connection. Students can also save money 
as they no longer must buy expensive books imported from Japan. More importantly, students can evaluate their understanding of the content learned from the website and send their feedback regarding the contents which would then help developers to further improve the content of the web site.

Mayer (2009) states that students can learn better when materials provided in the multimedia courseware contain both words and pictures as opposed to words only. In addition, Mayer (2009) believes that multimedia presentations which contain pictures help enhance students' understanding of the contents being displayed. The results of the study by Mayer (2009) show that adding a picture to a word increases students' understanding as it makes learning more meaningful. In contrasts, insertion of unrelated words and pictures in a multimedia courseware would cause the brain to disorientate and clutter, making it difficult for students to associate the unrelated words to the images depicted in their minds.

Students with high level of intelligence can create, construct, and use and view images in their own way. Hence, they do not require a multimedia courseware of good and high-quality design as words are sufficient for them. On the contrary, those with lower level of intelligence would require multimedia courseware that is supplemented with words either in the form of text displayed on the screen or in the form of repeat commentary. Several (Frear \& Hirshbuhl, 1999; Vignola, Kenny, Andrews, \& Schilz, 1999; James, 1999; Vrtacnik et al., 2000; Buckley, 2000; Cairncross \& Mannion, 2001; Almekhlafi, 2001; 2006) have proven that the use of multimedia has a positive effect on students' learning ability; however, there are also studies that have found otherwise (Smith \& Woody, 2000; McKethan, Everhart, \& Sanders, 2001; Vichitvejpaisal et al., 2001; Nutta et al., 2002; \& Hayes, Taub, Robinson III, \& Sivo, 2003).

To conclude, the use of multimedia in assisting UPM students to learn the Japanese language, particularly in vocabulary and grammar, has not been looked at. Thus, the present study acts as a platform to explore the effect of using interactive multimedia website in learning the Japanese language among UPM students.

\section{Why Interactive Multimedia Website}

Theoretically, learning basic Japanese language using the interactive multimedia website is based on the Cognitive Theory of Multimedia Learning (CTML). CTML was initially proposed by (Mayer, 2005) who stated that e-learning courses should be constructed considering how the mind learns and experiments evidence concerning e-learning features that promote best learning. This theory is based on three assumptions:

- Humans have separate channels for processing visual and auditory information (dual channels).

- Humans are limited in the amount of information that can be processed in each channel at one time (limited capacity).

- Humans engage in active learning by attending to relevant incoming information, organizing selected information into coherent mental representations, and integrating mental representations with other knowledge (active processing) 


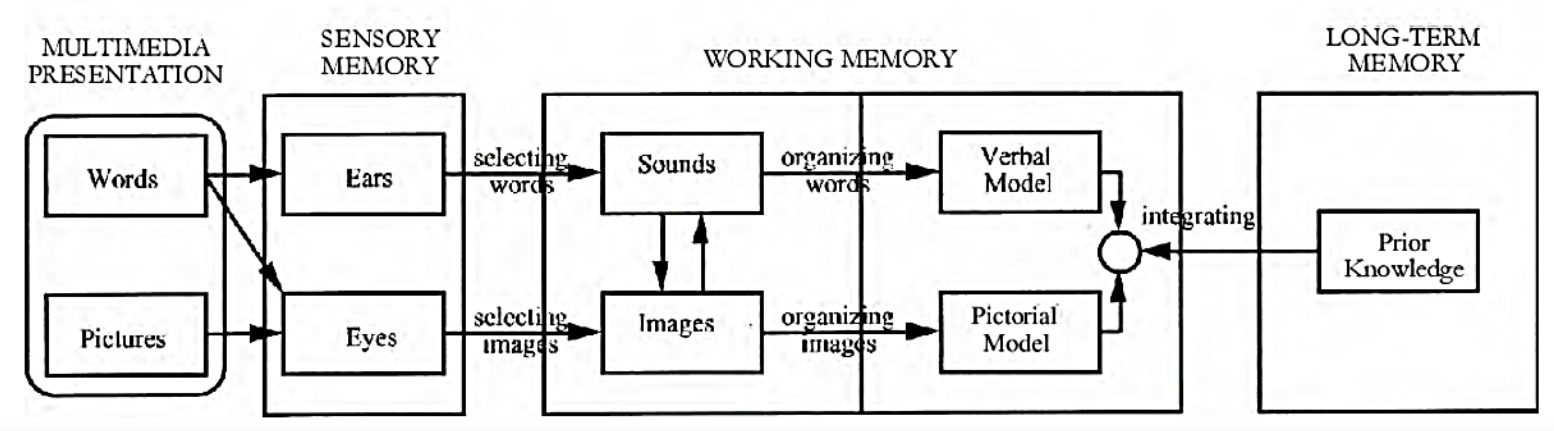

Figure 1: Adapted from Mayer's Cognitive Theory of Multimedia Learning (2005)

CTML (Mayer, 2005) describes aspects of image processing, spoken words and printed images. The selection and preparation of appropriate words and images will occur regularly in a person's memory storage when a teaching presentation via multimedia takes place. Through this theory too, other principles are also presented, namely, the principle of spatial balance, time balance, modalities, individual differences, and repetition. To facilitate the acquisition of a foreign language, multimedia can be used to increase inputs and tendency to observe which would enhance understanding. Multimedia-related strategies that have been used to support the ability to observe include word marking, sentence and linguistic characteristics. For example, students become engaged in understanding new words due to the explanations provided in the multimedia website through activities such as matching words with the correct images. Input enhancements for aural input using multimedia include the use of caption text, non-verbal signals (e.g., additional video images), instant feedback to audio auditory hearing, and repetition.

Interactivity refers to the mutual actions between the learner, learning materials, and learning system. Various studies have shown that interactivity has a strong positive effect on learning. Using interactive multimedia, learners can learn faster and have better attitudes toward learning. Moreover, Japanese language learners can learn independently, anytime and anywhere, using the interactive multimedia website. In addition, this can reduce individual differences, resulting in freedom for learning. Such an interactive multimedia website can attract learners' attention and stimulate them so that they can keep track with the lessons.

\section{Interactive Multimedia Website Project}

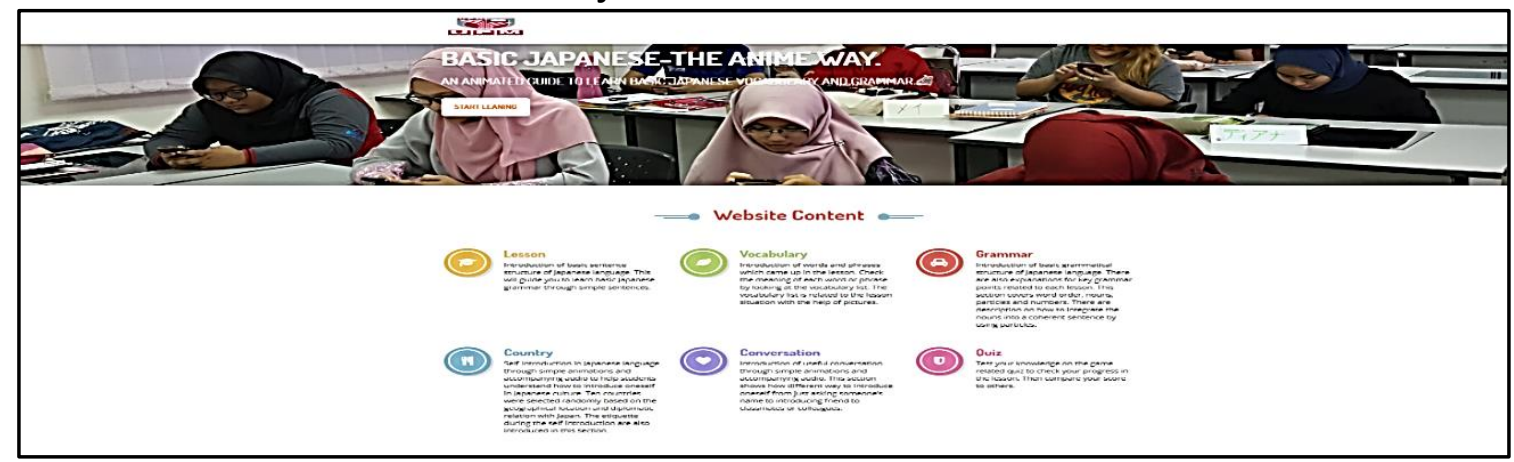

Figure 2: The Interactive Multimedia Website Project 
DEVELOPMENT

Vol. 10, No. 3, 2021, E-ISSN: 2226-6348 @ 2021 HRMARS

This web-based learning project was developed to enable users to learn basic Japanese language vocabulary items and grammar using the e-learning platform application. Incorporating multimedia such as animation, songs, graphic, movies, and the Internet might prove to be successful in turning traditional classrooms into communicative and studentcentred classrooms. Media such as movies or documentaries are among the best means for providing authentic speech and conversations. They are the 'replica' of everyday dialogues. This will lead to a better foreign language teaching and learning experience (Yun, 2014).

This web-based learning project was developed based on two topics, "Self-Introduction" and "How much is it?" Each topic consists of six modules, i.e., lesson module, vocabulary module, grammar module, country/ building module, conversation module and quiz module. The expected outcomes from these six modules after the completion of the lessons are that users will be able to read, write, speak, and listen at the beginner level. The lesson module in each topic developed for this website consists of sentence patterns which users need to acquire. The vocabulary module introduces vocabulary items in flash cards to assist users to learn them in Japanese as well as in English. The grammar module highlights the grammatical aspects to be learned in each topic. The country/building module is designed in animated dialogues to allow users to learn simple dialogues in a fun way while the conversation module is designed to introduce users to more complex dialogues using animation. Lastly, the quiz module allows users to take a quiz to test their understanding of the basic Japanese language. The responses provided by the questionnaire distributed to users indicated that in general, they are satisfied with the usability of the website.

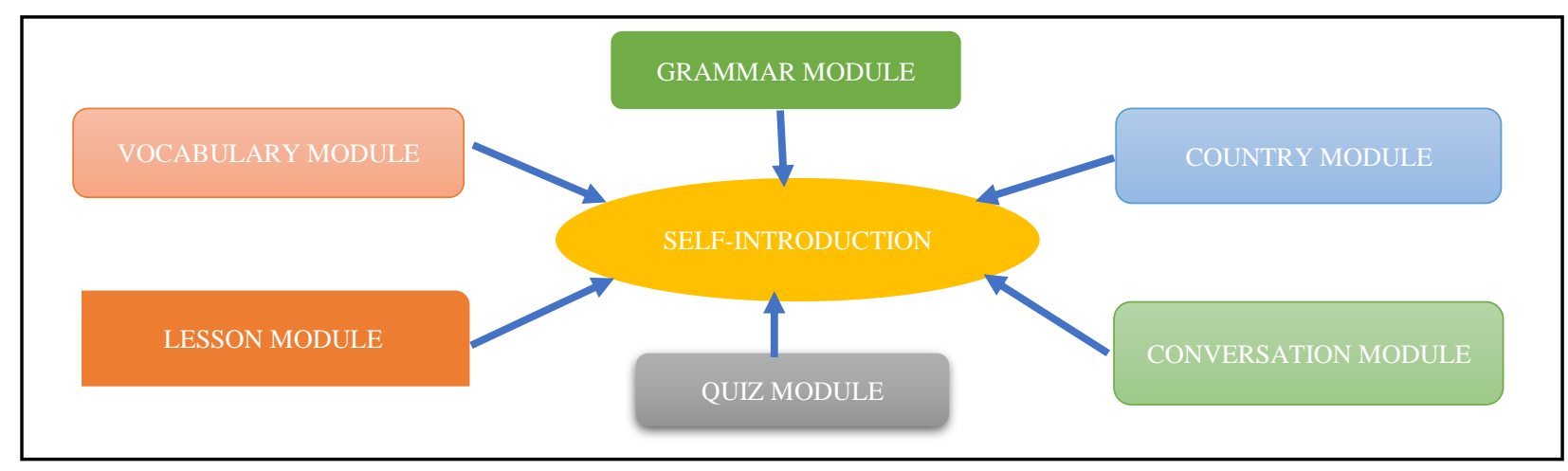

Figure 3: Interactive Multimedia Website 1

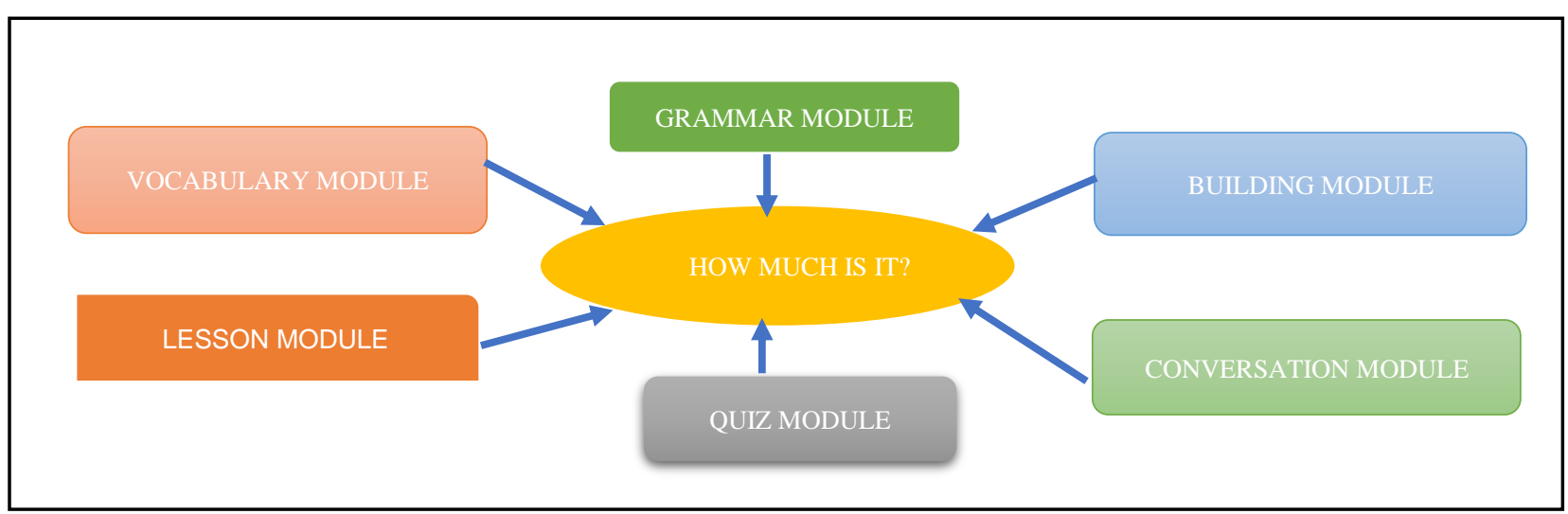

Figure 3: Interactive Multimedia Website 2 
The interactive multimedia website targeted users who wish to learn basic Japanese language. The interactive multimedia website offers an attractive educational software for students to learn the basic Japanese language on their own. This is because the interactive multimedia website includes graphics, texts, audios, videos, and animations that help students understand the information and content easily. In addition, an interactive multimedia website of a good quality helps motivates and attracts students to learn more. The interactive multimedia website contains embedded voice for the lesson and vocabulary modules. Therefore, students can learn how to pronounce the words correctly while at the same time, absorb and memorize the lessons easily. It will help them a lot in learning the Japanese language.

The interactive multimedia website project was funded by the Teaching and Learning Innovation Grant granted by the Centre for Academic Development (CADe), UPM in 2016. The design of the interactive multimedia website was developed by the researcher and coresearcher with the guide and help of a professional web designer. The whole project took about a year to accomplish before the copyright of the project was transferred by the developer to the researcher upon receiving payment from the research grant provided by UPM. The complete set of the interactive multimedia website project was then used as learning materials to help UPM learners acquire the basic vocabulary and grammar of the Japanese language.

\section{Methodology}

\section{Research Design}

This study applied the qualitative approach method. Qualitative observation and interview were chosen since this study is an exploratory study. Stebbins (2001b) describes exploratory research as "a brief, fleeting, preliminary stage in the research process that gives way to 'the sooner the better' to the real thing". The main objective of the study was to explore and investigate the effect of interactive multimedia website in learning the Japanese language in UPM. A semi-structured interview was conducted to gain insights on the students' perception of the usage of interactive multimedia website in learning the basic Japanese language. Field notes were made on the observation done on selected students who have used the interactive multimedia website in learning basic Japanese. Interviews were carried out in a duration of between 30 minutes and one hour based on the notes made by the selected students on learning basic Japanese. All qualitative data obtained from the structured interviews and observation were analysed using TI Atlas.

\section{The Participants}

The present study used the stratified purposive sampling method in selecting informationrich participants for the most effective use of limited resources (Patton, 2002). The participants comprised 30 students ( 15 males and 15 females) learning the Japanese language at the beginner level as an elective subject. They were between 20 and 25 years of age and of different backgrounds regarding ethnicity, faculty, origin, education, and economy. However, all the participants shared one common particular interest in Japanese popular culture. This includes anime, manga (Japanese comic or graphic novel), J-pop music, J-drama, video games, and cosplay (the practice of dressing up as a character from a movie, book, or video game). Since all the 30 participants involved were at the beginner level, they were encouraged to 
DEVELOPMENT

Vol. 10, No. 3, 2021, E-ISSN: 2226-6348 @ 2021 HRMARS

immerse themselves in a foreign language learning environment and gradually build up basic vocabulary to allow them to meet the objectives of the lessons taught in the classroom. The participants were asked to fill in a consent form to grant the researcher the permission to use the data obtained.

\section{Data Collection Instruments}

The data collection instruments chosen for this study included interactive multimedia web site, structured interview questions, and classroom observation notes. The structured interview questions were used to measure the attitudes, opinions, and perceptions of the participants while the data from the class observation were used to gather additional data to support the data obtained through the interviews.

\section{Data Collection}

The study was conducted for fourteen weeks during the first semester to assess the effects of the use of interactive multimedia website in learning basic Japanese language. At the beginning of the semester, participants were informed that an interactive multimedia website would be used in selected lessons. Each selected participant was given a consent form at the beginning of the study. Structured interview sessions were carried out to gather more information on the attitudes, opinions, and perceptions of the participants on the use of interactive multimedia website while class observation was carried out to investigate the behaviour of the participants while learning basic Japanese language using the interactive multimedia website.

\section{Data Analysis}

Qualitative data obtained from the structured interviews were transcribed to extract more information on participants' attitudes, opinions, and perceptions about the use of interactive multimedia website. Data obtained from the structured interviews were analysed using $\mathrm{TI}$ Atlas software. In addition, observations were conducted in the classroom to get useful information on the behaviour of the participants while learning basic Japanese language using the interactive multimedia website. One of the methods to ensure data reliability was by implementing a triangulation between the research methods (Wiersma, 1991; John, 1983).

\section{Findings}

Participants' Perception of the usage of interactive multimedia website in learning basic Japanese language

Content analysis was used to identify participants' perception on the use of interactive multimedia website in learning basic Japanese. Interview data were analysed using TI Atlas software, and responses from the participants were categorized into five main findings:

i) Content of the lesson

ii) Presentation of the lesson

iii) Understanding of the lesson

iv) Teaching and Learning Conditions

v) Feedback on the lesson 
DEVELOPMENT

Vol. 10, No. 3, 2021, E-ISSN: 2226-6348 @ 2021 HRMARS

Figure 4 summarizes the perceptions of the students on the effect of the use of interactive multimedia website in learning basic Japanese:

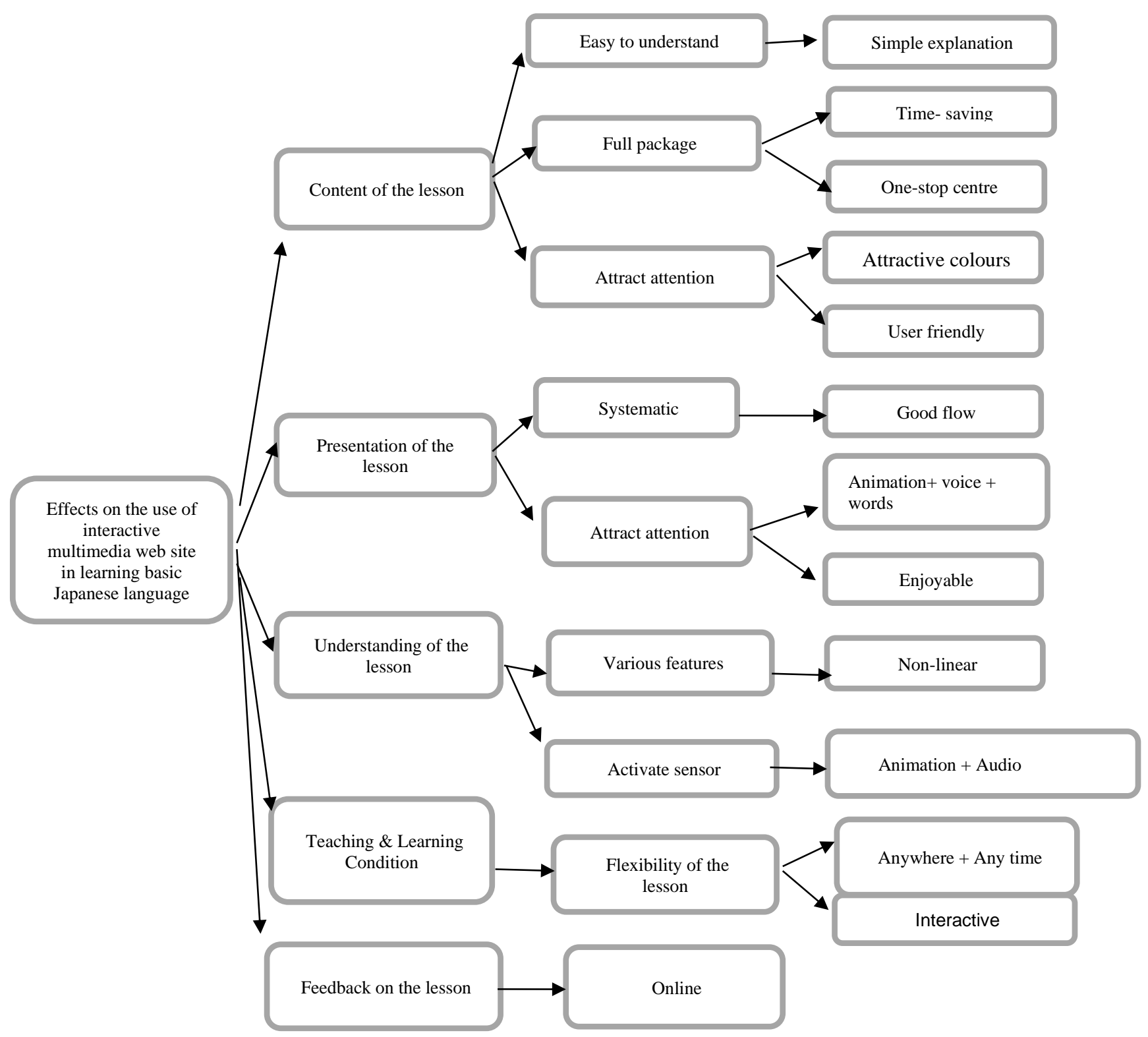

Figure 4: Summary of Students' Perception on the Effects of Interactive Multimedia Website in Learning Basic Japanese Language

\section{Content of the Lesson}

The students claimed that they were able to understand the content of the lessons as they were presented easily using interactive multimedia website which incorporates multimedia effects such as animation, songs, graphic, movies, and the Internet. This has proven to be successful in making the traditional classrooms more communicative and student-centered. Moreover, the website is a one stop center containing lessons and quizzes that facilitate selflearning and independent learning. In addition, the contents of the lessons are presented in a way that is easily understood, and the use of multimedia software also manages to deliver 
the lessons in an attractive manner to the students. Some of the students claimed that the colours used are vivid, and the website is user friendly.

A study by (Kulik et al, 1983) showed an $88 \%$ reduction in learning time with computerized instruction (90 minutes) compared to normal classroom instruction (745 minutes) while another study recorded a 39\% reduction in learning time (135 minutes for computerized instruction compared to 220 minutes for classroom instruction). Both studies involved computer simulation instructions in physics.

\section{Presentation of the Lesson}

In general, the presentation of the lesson was attentive, well organized, and systematic. Features such as colours, pictures, and sounds are among the elements that have helped students to identify important facts and eliminate sleepiness among students while learning using the multimedia software. Students enjoyed the lessons as the multimedia software allowed them to learn through animation, audio, and the wordings shown on the website in each lesson. According to [9], interactive multimedia is a good educational tool and is able to produce more positive effects to students with lower proficiency level compared to those with higher proficiency level.

\section{Understanding of the Lesson}

The concept and form of teaching and learning using interactive multimedia is non-linear and is in accordance to the students' ability level. This is because multimedia software is designed to work based on the logical development of the lessons i.e., from simple to hard and from low to high, according to students' cognitive level. Based on CTML (Mayer, 2005), meaningful learning takes place through cognitive active processes in choosing relevant information, organizing selected information into mental representation of forms, and integrating mental models with relevant existing knowledge from long-term memory. Besides, multimedia can activate students' senses through the colours, pictures, and sounds that ease understanding compared to the use of textbooks.

\section{Teaching and Learning Condition}

According to the students, multimedia-based teaching approach is flexible because students and teachers are free to choose any parts of the desired topic without having to follow a sequence, and the sound and animation elements make the descriptions clear and easy to understand. It is obviously different from the usual traditional approach used in schools. Using all of the multimedia attributes such as visuals, animations, colours, graphic, and audio, teaching becomes easy as the concepts conveyed become clearer despite language barrier faced by the teacher. This suggests that students can learn the lesson at anytime and anywhere in the e-learning platform to improve their basic Japanese language level during the learning process.

\section{Feedback on the Lessons}

According to the students, they were able to provide feedback and comments on the lesson online, and this helps in the improvements on the content and presentation of the interactive multimedia web site. This is a good way to share their responses to the lecturer on how to make the lessons on the website more attractive and interesting in the future. 


\section{The Behaviour of the Participants while Learning basic Japanese Language in the Interactive Multimedia Website}

After finishing the interactive multimedia website language learning process, the students were observed and given questionnaires to comment on the whole process of language learning. During the process of interacting with the interactive multimedia website, the teacher questioned some divergent and evaluation questions to the students. The students decide to learn basic Japanese using interactive multimedia website for several reasons; interested in Japanese language and culture, need a flexible time to study, and digital natives. Their comments on the use of the interactive multimedia website as a medium of online language learning are it has clear audio (90\%), it takes reasonable time to get connected and used the website (70\%), it has good image quality (95\%), it is user-friendly, enjoyable, and engaging (90\%). One of the advantages mostly mentioned by the students about the interactive multimedia website is that the application comes in attractive and engaging animation, audio, and activities. Therefore, the students became engaged in the learning process as they went through the lessons in a fun way while using the interactive multimedia website which also allows them to retrieve information related to the lesson and interact with ease.

The results of the observations revealed that students could easily access the interactive multimedia website. According to the respond from the students, the disadvantage of the interactive multimedia website is the disconnection and the slide lag during the e-learning process. The advantage of interactive multimedia website is its practical use, time and place flexibility, and the quality of the content which is not different from the face-to-face learning process. Meanwhile, the disadvantage of interactive multimedia website is its dependency to the internet connection. The internet speed determines the smoothness of the e-learning process. The students mention that the interactive multimedia website is very beneficial unique, and different from the conventional learning. Further, $100 \%$ of the students mention they will recommend interactive multimedia website as Japanese online language learning to their friends and colleagues.

\section{Discussion}

The use of interactive multimedia website has a positive effect on learning basic Japanese language as it enhances understanding, reinforces memory, and stimulates the senses so that learning becomes meaningful especially among students with low level of linguistic competence. This is important because the final learning outcomes that the student needs to achieve should display their ability in forming a simple and concise conceptual formulation mentally and relate a new concept into different situations in order for it to be translated as an easy-to-understand output. The interactive situation corresponds to the current student instinct without any pressure. The element of fun that triggers cheerful feeling during the learning process indirectly motivates the students and keeps their minds active during the learning sessions. In addition, animation facilitates the learning process because it is used sparingly and appropriately to highlight important facts. Animation also plays a role in assisting students reconstruct correct Japanese grammar, and this helps students form the relationship between words and sentences in their minds. The colour element combined into these multimedia integration components highlight what is being delivered in the lesson, and this can leave a good impression in the students' mind. 


\section{Conclusion}

The results of this study support the study by Mayer (2014) regarding the CTML which states that students can learn better and effectively if various media elements are used during the process of disseminating learning information through static and dynamical graphical presentation.

\section{Theoretical and Contextual Contribution}

This study is significant as it contributes to the stakeholders' understanding on the effectiveness between the utilization of an interactive multimedia website and vocabulary acquisition. This study can be used as a guide for foreign language instructors to understand better about a new teaching approach and maximizing interactive multimedia website in teaching and learning new vocabulary. Moreover, by using interactive multimedia website can enhance understanding, reinforces memory, and stimulates the senses so that learning becomes meaningful especially among students with low level of linguistic competence in teaching new basic Japanese vocabulary among students. Therefore, the use of interactive multimedia website in the learning Japanese vocabulary has a positive effect on improving the mastery of new Japanese vocabulary of students in a Malaysian university. The finding indicates that the interactive multimedia website is more recommended to be used for elearning. It is suggested that the developer of the interactive multimedia website to improve over time. This is necessary to support the process of e-learning. Through the improvement of the interactive multimedia website, the e-learning can be developed to wider areas which still have limited mobility access and limited number of Japanese teachers. Hence, the present study shows significant emergence of interest and the usage of the Japanese language learners on the interactive multimedia website.

\section{Acknowledgement}

This research was funded by the Incentive Grant for Research in Teaching and Learning (GIPP), Centre of Academic Development, Universiti Putra Malaysia.

\section{Corresponding Author}

Dr. Muhammad Alif Redzuan Abdullah

Universiti Putra Malaysia

\section{References}

Abdullah, M. A. R. (2005). Sikap Pelajar Cina terhadap Pembelajaran Bahasa Jepun di Universiti Putra Malaysia. Disertasi Universiti Malaya, Kuala Lumpur.

Abdullah, M. A. R. (2014). Strategi Komunikasi Lisan Bahasa Jepun Dalam Kalangan Pelajar Melayu di Malaysia. UnPublished PhD Thesis. Serdang: Universiti Putra Malaysia.

Abdullah, M. A. R., \& Hussin, S. (2019). The Impact of Animated Karaoke on Vocabulary Acquisition among Japanese Language Learners in Malaysian University. Indonesian Journal of EFL and Linguistic. 4(1), 1-14. http://dx.doi.org/10.21462/ijefl.v4i1.84

Abdullah, M. A. R., \& Hussin, S. (2020). The Impact of Composed Songs on Vocabulary Acquisition among Japanese Language Learners in Malaysian University. International Journal of Academic Research in Business and Social Sciences. 10(11), 904-914. http://dx.doi.org/10.6007/IJARBSS/v10-i11/7773 
DEVELOPMENT

Vol. 10, No. 3, 2021, E-ISSN: 2226-6348 @ 2021 HRMARS

Almekhlafi, A. G. (2004). The effect of interactive multimedia on learning English as a second language. Proceedings of the Fifth Annual UAE University Research Conference, 2. Al-Ain, United Arab Emirates.

Almekhlafi, A. G. (2006). The Effect of Computer Assisted Language Learning (CALL) on United Arab Emirates English as a Foreign Language (EFL) school students' achievement and attitude. Journal of Interactive Learning Research, 17(2), 121-142.

Buendia-Garcia, F. \& Diaz-Perez, P. (2003). A framework for the management of digital content conjugating instructional and technical issues. Educational Technology \& Society, 6(4), 48-59.

Buckley, B. C. (2000). Interactive multimedia and model-based learning in biology. International Journal of Science Education, 22(9), 895-935.

Cairncross, S., \& Mannion, M. (2001). Interactive multimedia and learning: Realizing the benefits. Innovations in Education and Teaching International, 38(2),156-164.

Frear, V., \& Hirschbuhl, J. J. (1999). Does interactive multimedia promote achievement and higher level thinking skills for today's science students? British Journal of Educational Technology, 30(4), 323-329.

Maaneen, J. V. (1983). Qualitative Methodology. Beverly Hill, California: Sage Publication

Harasim, L. (2000). Shift happens: Online learning as a new paradigm in learning. The Internet and Higher Education, 3, 41-61.

Kulik, J. A., Bangert, R. L., \& Williams, G. W. (1983). Effects of computer-based teaching on secondary school students. Journal of Educational Psychology, 75, 19-26.

Mayer, R. E. (2005) "Introduction to multimedia learning". The Cambridge Handbook of Multimedia Learning. New York: Cambridge University Press.

Mayer, R. E. (2009). Multimedia Learning. New York. Cambridge University Press.

Mayer, R. (2014). 'Cognitive theory of multimedia learning'. The Cambridge Handbook of Multimedia Learning. Cambridge: Cambridge University Press.

McKethan, R., Everhart, B., \& Sanders, R. (2001). The effects of multimedia software instruction and lecture-based instruction on learning and teaching cues of manipulative skills on preservice physical education teachers. Physical Educator, 58(1), 2-13.

Kamaruddin, N. (2010).Challenges Of Malaysian Developers In Creating Good Interfaces For Interactive Courseware, Turkish Online Journal Of Educational Technology, 9(1), 3742

Nutta, J., Feyton, C., Norwood, A., Meros, J., Yoshii, M., \& Ducher, J. (2002). Exploring New Frontiers. New Frontier.

Patton, M. Q. (2002). Qualitative Research \& Evaluation Methods. Thousand Oaks, CA Sage Publications.

Sabri, N. M., Isa, N., Daud, N. M. N., Aziz, A. A. (2010). Lecturers' Experiences in Implementing Blended Learning Using i-Learn. Proceeding of International Conference on Science and Social Research. Kuala Lumpur: Universiti Teknologi MARA.

Smith, S. M., \& Woody, P. C. (2000). Interactive effect of multimedia instruction and learning styles. Teaching of Psychology, 27(3), 220-223.

Stebbins, R. A. (2001b). Exploratory research in the social sciences. Thousand Oaks, CA: Sage. Vignola, Kenny, Andrews, \& Schilz. (1999). Interactive multimedia and teacher trainer for French as a second language: Program evaluation. Canadian Modern Language Review, 56(1): 180-202. 
INTERNATIONAL JOURNAL OF ACADEMIC RESEARCH IN PROGRESSIVE EDUCATION AND

DEVELOPMENT

Vol. 10, No. 3, 2021, E-ISSN: 2226-6348 @ 2021 HRMARS

Vrtacnik, M., Sajovec, M., Dolnicar, D., Pucko, C., Glazar, A., \& Brouwer, N. (2000). An interactive multimedia tutorial teaching unit and its effects on student perception and understanding of chemical concepts. Westminster Studies in Education, 23, 91-105.

Yun, E. (2014). Teaching Arabic to Korean students using films. The New Educational Review, 37(3), 80-91.

Wiersma, W. (1991). Research methods in education. 5th ed. Boston: Allyn \& Bacon. 